\title{
Por um braqueamento mais rápido: identidade e racismo nas narrativas do álbum do cinqüentenário da imigração italiana no sul do Brasil
}

\author{
For a faster whitenning: identity and racism in the album's \\ narratives of the fiftieth anniversary of Italian immigration in \\ southern Brazil
}

\author{
Luis Fernando Beneduzi*
}

\section{RESUMO}

As questões étnico-raciais estão presentes transversalmente em toda a história brasileira, especialmente a partir do processo de independência, quando se buscou elaborar uma identidade nacional. A primeira autoimagem produzida pelo Brasil, no século XIX, é a de uma nação sem negros, formada pela união do bom selvagem e do bom português. A figura do escravo/negro também permanece como uma problemática importante no século XX, permitindo a criação de uma visão idealista de uma democracia racial brasileira, entrecruzada por críticas à mestiçagem e por uma polifonia do saberes médicoantropológicos. Nesse sentido, no álbum comemorativo dos cinqüenta anos da imigração italiana no Rio Grande do Sul, produzido em 1925, a positividade étnica dos imigrantes italianos é contrastada com a inferioridade de negros e mestiços, em uma leitura que mistura a idéia de branqueamento e a critica à mestiçagem. Enquanto é enaltecida a forma da colonização do sul do país, marcada pela exclusão das populações negras, é criticada a política da cruzamento de raças, sendo vista essa última como uma estratégia lenta para a purificação do sangue nacional.

PALAVRAS-CHAVE: Etnicidade. Representação. Identidade. Mestiçagem. história do Brasil. Italianos. Rio Grande do Sul.

\section{ABSTRACT}

The ethnic and racial questions are present transversally in the entire Brazilian history, especially from the independence process, when we observe the first tentative to build a national identity. The first auto-image elaborated by the country [Brazil], in the nineteenth Century, is about a nation without blacks, formed by the union between the "noble savage" and the "noble Portuguese". The slave/ black figure remains as a important problematic of the Twentieth Century, permitting the creation of a idealistic vision of the Brazilian racial democracy, crossed by miscegenation critics and by a polyphony of medical and anthropological knowledge. In this sense, in the fifty-years commemorative album of the Italian immigration in Rio Grande do Sul, printed in 1925, the Italians immigrants ethnic positivity is contrasted with the black and mestizos inferiority, in a lecture that mix the "whiten" idea and the miscegenation critic. While the colonization method in the south of Brazil marked by the exclusion of the black population is glorified, the race miscegenation's politic is criticized, because its perception as a slow strategy to purify the national blood.

KEY-WORDS: Ethnicity. Representation. Identity. Miscegenation. Brazilian history. Italian. Rio Grande do Sul.

\footnotetext{
* Doutor em História pela Universidade Federal do Rio Grande do Sul (UFRGS) / Brasil com PósDoutorado em História na Università degli Studi di Torino (Itália) e Professor na Università Ca' Foscari di Venezia (Itália). Email: luis.beneduzi@unibo.it
} 
Nessuno è 'primitivo' in sé, e allo stesso modo, nessun popolo è, per natura, 'primitivo'. Il primitivismo eil primitivo sono delle rappresentazioni sociali, o meglio delle costruzioni immaginarie sul mondo che danno significato al reale.

Sandra Pesavento (2007, p. 483).

A noção de primitivo, assim como a percepção de uma inferioridade e de uma superioridade raciais, são fenômenos socialmente construídos e, também, historicamente produzidos. Pertencendo a processos de auto-identificação e conceituação do outro, envolvem o olhar daquele que enuncia e classifica, em uma relação comparativa, que determina quais são os indivíduos que compõem o grupo de superiores e quais são aqueles que fazem parte do grupo de inferiores. Certamente, o sujeito que classifica, o faz em relação a sua experiência histórica e social, atribuindo ao "diferente" um grau negativo, visto que em contraste com a sua realidade sóciocultural, naturalmente positiva. Efetivamente, pode ser percebido, na fala de quem produz essa cartografia social, um poder simbólico importante de dar a conhecer o que é o real.

Nesse sentido, quando se fala em uma idéia de inferioridade racial, de um primitivismo, seja ele a partir do olhar da eugenia e do darwinismo social, de finais do século XIX e início do século XX, seja a partir de uma perspectiva culturalista, está-se discutindo, também, processos de construção de identidade. Na medida em que os diferentes grupos passam a orientar e organizar as suas vidas a partir desse conceito e dos sentidos que ele traz consigo, atribuindo significados às suas práticas quotidianas, essa percepção se transmuta em parte de sua identidade.

A concepção de uma hierarquia racial entre as sociedades humanas constituiu-se em uma marca importante das representações sociais dos sé-culos XIX e XX, sendo responsável pela elaboração de imaginários cole-tivos que envolvem as diferentes comunidades nacionais. De fato, o mo-mento de seu florescimento irá coincidir com a agudização de processos nacionalistas, nas dinâmicas de construção dos Estados-nacionais, e com um conseqüente aumento na percepção das minorias étnicas ao interno das nações. Essas questões permitem uma compreensão maior sobre os processos de reelaboração constante do imaginário que, como afirma Baczko, apresenta contornos diferentes de sociedade a sociedade e é histori-camente construído: 
[...] as modalidades de imaginar, de reproduzir e renovar o imaginário, como as de sentir, pensar e criar, variam de uma sociedade a outra, de uma época a outra e por conseguinte, tem uma história (BACZKO, 1991, p. 27).

Assim, cada momento histórico constrói classificações de positividade e negatividade, regras de comportamento, produz, inclusive, modelos normativos que fazem compreender a maneira como um grupo enxerga a realidade e com ela se relaciona. No entanto, deve-se ressaltar que - como no caso das leituras sobre as hierarquias raciais e sobre a degeneração do sangue, tema que se aprofundará mais adiante e que apresenta diferentes perspectivas de análise e leituras- as representações sociais são elaboradas em um contexto de conflito entre diferentes percepções da realidade. Portanto, um determinado imaginário social consegue colocar-se como "consensual" na medida em que se observa um processo de ressonância com o real e com as experiências de uma dada comunidade. Ele acaba por convencer o grupo de seu valor enquanto leitura mais verossímil da realidade, enquanto elemento mais qualificado para a coesão da comunidade.

Pensando essas questões, o objetivo central deste artigo é discutir uma determinada leitura positiva da influência étnica e social dos imigrantes italianos no Rio Grande do Sul, em contraste com as teorias da democracia racial e da regeneração dos "males que vêm com o sangue", a partir do processo de braqueamento. No texto de Francisco de Leonardo Truda (1925), cuja análise será aprofundada mais adiante, é enaltecida uma experiência de colonização que coloca o negro à margem das colônias italianas e que vive um processo singular de assimilação. Essa perspectiva de análise, mais do que a simples expressão de um olhar racista diante do contato entre italianos e negros, pode ser lida como parte de um processo de elaboração das teorias sobre o sangue e a raça no Brasil, o qual se cruza com a história do primeiro século da independência brasileira, trazendo à luz diferentes momentos de construção da identidade nacional.

\section{Um Império Escravocrata e "Sem Negros"}

Uma primeira etapa, para que se possa compreender a preocupação brasileira com a questão racial e para que se possa percorrer o processo de elaboração das teorias raciais no Brasil, tem início com a independência do país. A partir de 1822, com a separação política de Portugal, o Estado que nasce precisa se construir como nação, isto é, elaborar uma identidade nacional que permita o crescimento de uma coesão interna. Não pode ser esquecido que o Brasil, sobretudo nos vinte e cinco primeiros anos da 
independência, deverá lutar com importantes forças centrífugas e, portanto, contra a desagregação do antigo território colonial. As primeiras escolhas pós-independência centralis-mo político e monarquia- levarão em conta esse grande medo da fragmentação e da perda de poder que assombra a elite brasileira.

Dessa forma, a grande questão que se colocará nos primeiros anos do Império será referente a um importante questionamento: qual imagem se constituirá enquanto representação do Brasil e do povo brasileiro. A identidade, obviamente, deve ser um elemento de coesão nacional, de auto-identificação; portanto, apresenta-se como uma força de atração e de reconhecimento entre a nação "inventada" e os indivíduos que a compõe:

A identidade, como construção imaginária de pertencimento e invenção do mundo, precisa que os indivíduos nela se reconheçam. É necessário, então, que ela seja atraente e que os personagens, os eventos, as datas e os hábitos possam ser identificados e reconhecidos como verdadeiros, e que, de certa maneira, eles sejam reconhecidos como portadores das qualidades desejadas (PESAVENTO, 2007, p. 484).

Com efeito, a política de Estado deveria conceber, então, símbolos que representassem e singularizassem essa jovem nação e - acima de tudo- produzir uma memória que construísse a idéia de uma trajetória comum. Para tal fim, como recorda Lilian Moritz Schwarcz (1998), será criado o Instituto Histórico e Geográfico Brasileiro, em 1838, que viverá o seu apogeu - em meados do século XIX - com a atuação constante do imperador, D. Pedro II. Essa instituição será a grande responsável pela elaboração da identidade nacional brasileira, fortalecendo a imagem do imperador, em sua união com as grandes monarquias européias e com o que havia de melhor na terra brasileira.

Nesse contexto de formação de um certo povo brasileiro, a questão da escravidão africana - e a figura do negro- colocava-se como grande elemento de conflito, na busca de uma homogeneização do Brasil. Soma-se a isso, a vontade brasileira de aproximar-se das grandes nações européias, marca importante de uma nação que nasce e se desenvolve de costas para a América Latina e voltada para a Europa. Assim, coloca-se o grande problema de como vincular-se as grandes potências do velho continente, sempre mais defensoras do liberalismo, carregando consigo as feridas do atavismo, presentes na estrutura escravista.

A resposta brasileira foi caracterizada por uma dinâmica que acabou acompanhando o negro na história da sociedade nacional: a exclusão. Com isso, o processo de construção de uma identidade para a nação esteve baseado - 
fundamentalmente- na negação de uma marca de africanidade, ou seja, de negritude. Sendo assim, a auto-representação do povo brasileiro, a qual se configurava especialmente a partir do Romantismo, tanto no Instituto Histórico e Geográfico quanto na Academia de Belas Artes, fundou-se no cruzamento entre o "bom português" e o "bom selvagem" nacional. Logo, desde o início, a marca por excelência que se buscava dar a identidade brasileira era de branquitude (SCHWARCZ, 1998).

A literatura, a pintura e a história celebraram o "bom selvagem" que se sacrifica completamente para que ocorra o nascimento da nação, um índio que é privado de suas características étnicas e é declamado a partir de um cânone estético europeu. Personagens como Iracema, Peri ou o bravo guerreiro tupi, que se joga sozinho na luta contra os Timbira, para por eles ser devorado, em um ritual antropofágico, marcam essa representação de um indígena honrado e corajoso que um romantismo à brasileira está construindo, a partir de clássicos como Gonçalves Dias, José de Alencar e Gonçalves de Magalhães.

O Estado Nacional reforçava uma determinada imagem da nação, como uma forma de negar um outro grupo, o qual se constituía na força maior da produção nacional, o escravo. O índio, para além da questão específica do trabalho forçado, diferentemente do negro, representava uma miscigenação mais suave, na medida em que seus traços diluíam-se em sucessivas gerações. O escravo africano trazia consigo a força da permanência de traços fisionômicos indesejáveis, deixando como que uma marca de Caim em uma elite que se queria pura:

Com os negros, não. O drama era que - misturados com os brancosdeixavam marcas tão fortes sobre a pele, no rosto e nos cabelos, que assinalavam, de qualquer forma, uma presença e que remetiam a ancestrais indesejáveis que recordavam a escravidão (PESAVENTO, 2007, p. 486).

Preteridos com relação aos índios, imagem mais original dos míticos habitantes da "terra brasilis", os negros vão começar a perder espaço, também, diante dos novos trabalhadores que começam a chegar, sempre em maior quantidade, durante o século XIX, os imigrantes europeus. As tentativas de atrair a mão-de-obra européia para o Brasil se confundem com a vinda da família real, no entanto, somente a abertura do mercado de trabalho e o aumento da propaganda brasileira na Europa, acabaram por criar um fluxo massivo de imigrantes que se dirigiu para as províncias brasileiras.

Neste novo contexto, no qual ver-se-á mais uma vez a renegação dos negros, é que começa a discussão acerca de qual povo e qual raça se quer como parte da nação brasileira. Mesmo ainda não estando delineadas as teorias raciais que determinariam 
a classificação entre imigrantes desejáveis e indesejáveis, o congresso brasileiro permite uma primeira leitura sobre quais grupos étnicos eram bem-vindos ao Brasil. Como recorda Luiz Felipe de Alencastro, no debate parlamentar sobre a importação de mão-de-obra chinesa para o Brasil, em 1857, já se pode observar "os condicionantes culturais" que marcariam a política imigrantista brasileira (ALENCASTRO, 1999). Efetivamente, as discussões parlamentares diante do caso chinês mostram - além de uma questão identitária, perceptível especialmente na burocracia imperial- uma preocupação da elite nacional, fundada na grande propriedade agrícola para a exportação, relativa à força de trabalho.

No entanto, o tráfico de chineses acaba sendo vetado, assim como uma outra proposta, encaminhada à Assembléia Legislativa da província do Rio de Janeiro, de importação de africanos livres. Segundo Alencastro, o “J ornal do Comércio" comemora a derrota dos projetos, sobretudo daquele relativo aos imigrantes provenientes da África, pois entendia que somente colonos europeus poderiam regenerar o atraso agrícola do país, gerado pelos escravos africanos. Está-se vivendo um momento de transformações na percepção do outro e, progressivamente, o negro e outros grupos não-europeus começam a ser vistos negativamente, não somente por uma questão cultural, mas - também- por uma questão racial. Aliás, como poder-se-á observar mais adiante, esse cruzamento entre raça e cultura vai ser muito usual nos processos classificatórios brasileiros, com relação aos imigrantes desejados.

Assim, no transcorrer do século XIX, a idéia de um nacionalismo cultural vai sendo suplantada pela construção de uma identificação nacional marcada pela raça. Giralda Seyferth destaca que a importância de um nacionalismo demarcado pela língua e pelas tradições populares nacionais, passa a ceder lugar a uma descoberta do racismo, radicalização do darwinismo social e origem da eugenia (SEYFERTH, 1996). Na esteira dessa transformação, ver-se-á, ao longo do último quarto do século XIX, grandes levas de imigrantes europeus aportarem em terras brasileiras. Essa massa populacional deslocou-se fortemente impulsionada por uma agressiva política imperial de aliciamento, a qual foi implementada em todo o continente Europeu.

Ancorada na Antropologia Física e idealizada por personagens como Gobineau, Chamberlain e Lapouge, a determinação da superioridade racial branca percebia de forma negativa a mestiçagem. Entretanto, a intelectua-lidade brasileira, frente a essa tese da inferioridade do mestiço, construiu a teoria de um branqueamento em três gerações, o qual produziria uma população branca. Nesse intuito, elaborou-se um plano de regeneração nacional, a partir da vinda de imigrantes selecionados. Será nesse contexto, de uma intrínseca superioridade branca, que se dará o desembarque desses 
italianos, tanto em São Paulo quanto no Rio Grande Sul, sendo também esse o pano de fundo do período de festejamento do qüinquagésimo aniversário da imigração italiana, em terras sul-riograndenses, questão que será abordada mais adiante.

Portanto, como se pode denotar, o negro deixa de ser uma presença indesejada, tornada invisível, pela burocracia imperial e pelo grupo vin-culado ao Instituto Histórico e Geográfico e a Academia de Belas Artes, que estão desenhando um perfil do povo brasileiro, porque marca do es-cravismo e do atavismo, e começa a ser indesejável - diante do novo pen-samento médico-antropológico do último quartel do século XIX, em última análise "científico"- porque racialmente inferior. A libertação dos escravos e o advento da República irão agudizar esse preconceito sobre o negro - visto como raça- pois, segundo George Andrews, após a lei Áurea, o termo escravo, que era carregado de preconceito e trazia consigo o estigma da cor, deixa de existir e a marca negativa da subserviência é transferida à raça negra (ANDREWS, 1998).

\section{Entre Mestiçagem e Apartheid: a "Raça Negra" e o Projeto Brasileiro de Nação}

A questão do preconceito racial, a qual está muito presente na socie-dade brasileira, e as tentativas de ocultar os grupos de afro-brasileiros da memória nacional fizeram com que eles vivessem por tantos séculos um processo de exclusão da identidade concebida para o país. Essa realidade de ausência e a permanência deste "senso comum vinculado ao passado nacional" é a chave para compreender algumas experiências contemporâneas de desqualificação de uma participação negra na elaboração de uma auto-representação do Brasil. Possibilita, ainda, enquadrar as dificuldades vivenciadas por Andrews, nos anos 90, para a publicação de sua obra, em português, relatadas no prefácio à edição brasileira, porque "negro" é um tema sem visibilidade e pouco interessante:

\footnotetext{
Mas, no caso específico deste livro, me informaram as editoras com as quais falei (e falei com muitas), os obstáculos foram maiores ainda. 'Qualquer livro sobre negros não vai ter mercado,' asseguraram-me. 'Salvo alguns intelectuais, ninguém quer saber deste tema. Desculpe a nossa franqueza, mas o seu livro é simplesmente ineditável no Brasil' (ANDREWS, 1998, p. 15).
}

Essa marca de "não importância" no que se relaciona às questões que envolvem os grupos de etnia afro-brasileira se, por um lado, tem um forte vínculo com a cultura escravista vivida no Brasil, até finais do século XIX, por outro, traz à luz a permanência 
- mesmo em nível não consciente- de uma hierarquia de positividades sociais, dentro da qual o negro se encontra no degrau mais baixo. Esse percurso desqualificador do negro - vivido com muita intensidade a partir das últimas décadas do Oitocentostrouxe consigo tentativas teóricas e empíricas de apagamento desse sinal de degenerescência, pois ele comprometia o futuro da nação.

Destaca-se, no entanto, que a questão das teorias raciais e da própria eugenia durante a transição do século XIX para o XX, e mesmo no período de comemoração do cinqüentenário da imigração italiana- não apresentava, em nível mundial, um consenso; existiam muitas variáveis que participavam da discussão científica, não sendo possível observar uma posição plenamente consensual:

\begin{abstract}
Não é recomendável tentar cristalizar as orientações teóricas que se apresentavam naquele momento, vários termos e conceitos ferviam no mesmo caldo: desde partículas hereditárias até genes; variações contínuas e descontínuas, seleção natural, artificial, geminal e influência do meio ambiente (CASTAÑEDA, 2003, p. 906).
\end{abstract}

Essa noção apresentada por Castañeda acaba permitindo entender as diferentes versões que se começa a observar nas análises médico-antropoló-gicas brasileiras, entre o Império e a República, bem como nas diferentes construções teóricas que farão parte das discussões científicas dos anos 1920. Assim, já em finais do século XIX, as teorias brasileiras apresentam ao menos duas visões conflitantes acerca da mestiçagem e por conseqüência- acerca do projeto de construção de uma imagem do povo brasileiro. Por um lado, tem-se uma percepção negativa sobre a mestiçagem, como degenerescência e fatalidade nacional; por outro, denota-se uma atenuação da questão racial e o envolvimento de outros fatores, mutáveis, no forjamento do atraso da nação:

\begin{abstract}
A primeira, que teve em Nina Rodrigues uma importante referência, alinhou-se mais a uma visão negativa quanto à composição racial e quanto às conseqüências da mestiçagem. Já a segunda, notadamente através de Roquette-Pinto, distanciou-se das noções de fatalismo racial, tendo chegado a se tornar uma eloqüente porta-voz de que a inferioridade dos mestiços brasileiros não seria estrutural (i.e., orgânica/racial), mas sim conjuntural, relacionada a fatores ambientais e sócio-culturais (SANTOS, 1998, p. 239).
\end{abstract}

Dessa forma, pode-se perceber que a percepção de uma regeneração do sangue nacional, conseguido a partir de uma política de branquea-mento, não era a única variável em jogo, embora fosse pouco a pouco se constituindo na versão mais aceita socialmente, tendo em vista as tenta-tivas de conformação do Brasil à sua representação de democracia racial. Vai ser justamente essa imagem vitoriosa da 
nação brasileira como espaço harmonioso do convívio entre raças diferentes, a saber brancos e negros, que acaba criando um estranhamento relativo a certas afirmações de exclusão racial presentes no álbum dos cinqüenta anos da imigração italiana no Rio Grande do Sul.

A partir do século XX, propaga-se uma imagem sempre mais aceita, inclusive em âmbito internacional, do Brasil como terra de oportunidades para todas as raças, onde o negro tem toda a liberdade de crescer e de-senvolver suas potencialidades. Mesmo antes de Gilberto Freyre, o povo brasileiro era descrito - sobretudo autorepresentado pelos meios de comunicação- como um paraíso racial; em contraposição aos Estados Unidos, terra de lutas entre brancos e negros, lugar de desigualdade e conflito. De fato, a "nossa" mestiçagem estava, na medida em que conduzia à atenuação dos traços africanos, dissolvendo as marcas de conflituosidade no território nacional.

De qualquer forma, essa percepção ufanista de uma nação plena de democracia e cidadania, na qual todos participavam paritariamente do pro-cesso produtivo e decisório, sem discriminação de cor, aumentava eficácia de uma idéia de inferioridade intrínseca à raça negra. Como afirma George Andrews, se as condições de ascensão social são paritárias, se as possibilidades de sucesso são iguais para todos os indivíduos; então, a única explicação para a condição dos negros, no Brasil, está vinculada aos "males que vêem com o sangue":

Se os negros fracassaram em sua ascensão na sociedade brasileira, evidentemente isso foi por sua própria culpa, pois essa sociedade não reprimiu nem obstruiu de modo algum o seu progresso. A realidade continuada da pobreza e marginalização dos negros não era vista como uma refutação da idéia de democracia racial, mas sim como uma confirmação da preguiça, ignorância, estupidez, incapacidade, etc., o que impedia os negros de aproveitar as oportunidades a eles oferecidas pela sociedade brasileira - em suma, um restabelecimento da ideologia da vadiagem (ANDREWS, 1998, p. 210).

Na própria aceitação da negatividade, por parte de diferentes grupos negros, no Brasil, encontra-se presente uma prova irrefutável da força de uma imagem de deficiência genética das populações de afro-brasileiros. O imaginário coletivo que reproduz essa representação de uma inferioridade ontológica dos grupos étnicos provenientes da África adquire tamanha ressonância na comunidade que convence ao próprio grupo étnico, o qual passa a considerar esse atributo parte de sua essência. Em uma leitura sincrética, que mistura fatalismo racial e influência do meio, os jornais étnicos questionam o preconceito, justificando que a sua condição de atraso não pode ser causa de tal atitude: 
Não discutiremos as origens científicas do atraso da nossa forte e heróica raça [...]. E porque sejamos representantes de uma raça inferior, devemos ser condenados à força do preconceito racial? Que culpa temos nós dessa nossa triste condição humana na história dos povos? [...]. A culpa não é nossa, interrogae os quatrocentos anos de nosso ferrenho captiveiro, interrogae o miserável regimen de obscurantismo em que fomos criados, interrogae a lei do atavismo e da hereditariedade [...]. (ANDREWS, 1998, p. 212).

Mas uma certa parcela do grupo negro não termina sua fala no reconhecimento de sua vileza, assume, inclusive, a teoria do branqueamento como maneira de qualificar a sua raça. No jornal "O Bandeirante", em um repúdio à origem africana, afirma-se o desejo de sacrificar a própria raça como forma de ocupar um espaço mais qualificado na hierarquia eurocêntrica dos grupos humanos: “Não pretendemos perpetuar a nossa raça, mas, sim, infiltrarmo-nos em o seio da raça privilegiada - a branca, pois, repetimos, não somos africanos, mas puramente brasileiros". (ANDREWS, 1998, p. 213).

A década de 1920, segundo Jair de Souza Ramos, assistirá a uma gradual diminuição na importância das discussões sobre o racismo científico como uma maneira de compreender o Brasil e o povo brasileiro, uma especificidade que segundo o autor- difere da experiência mundial (RAMOS, 2003). No entanto, um acontecimento vinculado às políticas de imigração brasileiras e a representação da mítica democracia racial trará à luz - mais uma vez- a questão das diferenças dos grupos humanos.

Em 1921, estimulados pela imagem de igualdade racial que chegava do Brasil, um grupo de afro-americanos decide organizar um projeto de emi-gração, para formar grupos de colonização, no interior do território brasi-leiro. Essa solicitação cria uma situação complexa para a diplomacia brasi-leira e para o congresso nacional, e gera uma crescente discussão publica sobre a questão "cor". Em um país que via com bons olhos a importação de mão-de-obra estrangeira, que em diferentes momentos subvencionou a vinda de imigrantes, uma simples resposta negativa não seria justificável. Além disso, os afro-americanos traziam consigo uma identidade hifenizada - por um lado eram africanos (negros), mas, por outro, eram cidadãos americanos.

Como afirma Tiago de Melo Gomes, a controvérsia gerada pelo pedido destes grupos de negros norte-americanos tornou manifesta uma situação de crise, problematizando a idéia do paraíso racial brasileiro. Questões como branqueamento e preconceito racial tornam-se a ordem do dia, pois a chegada desses "outros" poderia tirar o equilíbrio social vigente no Brasil e romper com a "paz nacional": 
[falando sobre a vinda dos imigrantes norte-americanos] Note-se que essa visão de que o problema racial brasileiro estaria resolvido e seria reativado por estes imigrantes acaba por colocar o branqueamento e a ausência de preconceitos no Brasil como fenômenos irmãos, ambos derivados da miscigenação racial (GOMES, 2003, p. 317).

Pensando nos grupos de afro-brasileiros, enquanto uma vertente criticava e via com maus olhos a vinda dos negros norte-americanos para o Brasil, porque prejudicaria o processo matemático de fenecimento da raça negra no território nacional; uma outra, contrária ao projeto de branqueamento, discutia este propósito de "arianização" brasileira, com o negro que deve ser aniquilado, em um processo de caldeamento das raças. Nesta segunda variante, alguns grupos afirmam que a situação racial brasileira, quando comparada com a norte-americana, não parece efetivamente vantajosa. A idéia do conflito entre negros e brancos nos Estados Unidos é vista como um elemento fortificador dos grupos de afro-americanos, pois a necessidade de defesa teria engendrado uma consciência diferente daquela dos grupos brasileiros: altiva, orgulhosa, combativa (ANDREWS, 1998).

O desfecho para a "questão norte-americana" vai ser estrategicamente articulado em um processo de desvinculação da problemática estritamente racial - grupos negros. A solução encontrada pelo governo brasileiro buscará destacar a agressividade dos grupos afro-americanos, o que se configura como uma diferença entre grupos nacionais:

Desse ponto de vista, não se trataria de barrar a entrada de "pretos", mas sim daqueles impregnados da hostilidade racial que seria característica dos Estados Unidos. Assim, argumentava-se que não era uma questão entre "brancos" e "pretos", mas uma caracterização nacional que separaria "Brasil” e "Estados Unidos" (GOMES, 2003, p. 318).

Certamente a hostilidade representava também uma noção de dificuldade de assimilação, de participação nesse processo de fusão de raças, esperança de uma nação menos identificada pela "marca de Caim". A identidade nacional que se quer forjar, como se depreende das questões elencadas acima, está marcada por um projeto de apartamento dos elementos identificadores da raça negra, seja por um processo gradual de desaparecimento, seja por um processo exclusão.

Ainda duas perspectivas mostram a efervescência dos anos 20 e a complexidade das discussões sobre a identidade nacional naquela década. Por um lado, ver-se-á um processo de revisitação da idéia de brasilidade com o movimento Modernista, e com a Semana da Arte Moderna de 1922, segundo o qual a alteridade era sinal da 
especificidade nacional; por outro, idéias como aquelas gestadas por Francisco J osé Oliveira Vianna, materializadas na obra "Raça e assimilação", publicada em 1932, retomam um determinismo biológico de tipo racial. Esse conflito estará presente em textos que participam do festejamento da imigração italiana, como o de Leonardo Truda, que será em seguida analisado.

\section{Assimilação, Exclusão e Branqueamento: Leituras sobre a Contribuição Italiana no Rio Grande do Sul}

Antes de prosseguir com a discussão sobre branqueamento e exclusão, é importante apresentar algumas questões sobre a memória do processo imigratório no sul do Brasil, que estava em pleno processo de construção quando da publicação do álbum comemorativo; era o primeiro momento de "balanço" sobre o que tinha sido feito pela comunidade italiana no Rio Grande do Sul. Destaca-se, ainda, que o festejamento ocorre em um momento especial para as comunidades de imigrantes, tendo em vista que - com o fascismo- surge o conceito de "italianos no exterior", o que produz um novo status para os grupos provenientes da Península Itálica.

Nesse momento, é reforçada, como memória de uma italianidade, a marca do imigrante como elemento civilizador/europeizador das terras devolutas do governo imperial. A rigor, percebia-se, nesse egresso de terras européias, a possibilidade de desenvolver econômico e socialmente essa região, ocupando os espaços "vazios". Entendido como racialmente superior - com relação mestiço brasileiro- esse emigrante da Península Itálica - branco- viria dar um sangue mais saudável ao elemento nacional, purificando a nação. Essa leitura do italiano como qualificador do povo brasileiro já era observável - inclusive- nos discursos parlamentares italianos de finais do século XIX (BENEDUZI, 2004).

Como se pode observar, vai ser no bojo das teorias racistas de finais do Oitocentos que se dará a grande onda imigratória de europeus para o Brasil. Dentre os tipos possíveis, será o italiano, por suas semelhanças lingüísticas e religiosas, um dos mais requisitados para esse processo de purificação do elemento nacional. Efetivamente, os cinqüenta anos que se passam entre o início da imigração e as festividades de 1925 são marcados por uma progressiva positividade do elemento branco/europeu, logo, de uma visão de sua presença enquanto fomentador de civilidade para a nação.

A rigor, a literatura sobre a imigração, produzida para o festejamento dos cinqüenta anos de "colonização" italiana, constrói figuras emblemáticas no transcorrer 
do processo de ocupação do solo, as quais serão elementos de identificação, a partir de uma vontade mágica de pertencimento:

O meio mercantilizado e estereotipado da cultura de massa se constitui de representações e figuras de um grande drama mítico com o qual as audiências se identificam, é mais uma experiência de fantasia do que de auto-conhecimento (SOVIK, 2003).

No caso específico do Rio Grande do Sul, o imigrante italiano será percebido como aquele trabalhador incansável que está construindo a grandeza e pujança do estado. Certamente, os traços psicológicos atribuídos a essas populações da Península Itálica têm uma relação direta com o progresso econômico que se começa a perceber na região, a partir do início do século XX. É neste contexto que se pode começar a apresentação da análise oferecida pelo texto de Francisco de Leonardo Truda, pois a sua leitura se insere nesta apologia da bravura da raça italiana e na sua capacidade de colaborar para com o desenvolvimento econômico e humano do estado.

Truda (1930) trazia consigo uma certa autoridade na fala, visto que estudava questões vinculadas a imigração européia, sendo que alguns anos depois das comemorações dos cinqüenta anos da chegada dos primeiros colonos italianos - em 1930 - ele vai publicar "A colonisação allemã no Rio Grande do Sul”. Constituía também- uma das vozes da imprensa gaúcha, a partir do jornal Diário de Notícias, fundado por ele em 1925, meio de comunicação que marcou o jornalismo regional.

Em alguns escritos contemporâneos, as idéias que expressa no texto são vistas como racistas, com a percepção atual do conceito: preconceito extremado contra indivíduos pertencentes a uma raça ou etnia diferente. Se, pelo contrário, busca-se ir além de um olhar anacrônico sobre o pensa-mento de Truda, poder-se-ia dizer que ele estava em sintonia com as dis-cussões de sua época e - de uma certa maneira- até poderia ser com-preendido como defensor do racismo, mas entendido como um conjunto de teorias e crenças que estabelecem uma hierarquia entre as raças. (HOUAISS, 2007). De fato, as suas idéias vão procurar dialogar com um importante expoente da discussão acerca da problemática racial no Brasil.

Apresentando diversas informações sobre questões como o cresci-mento vegetativo da comunidade italiana, a baixa mortalidade, a viva-cidade econômica e a boa higiene, Francisco de Leonardo Truda enaltece a imigração européia como regeneradora da população do Rio Grande do Sul. Não transformadora por meio de um processo de assimilação e mis-tura, mas por sua expansão (dos grupos étnicos europeus) pelo território do estado e conseqüente expulsão/exclusão das 
populações inferiores. Nesse sentido, salienta - explicando a constatação de Oliveira Vianna sobre o rápido branqueamento que se observava no sul do país- que a especifi-cidade do fenômeno de clareamento gaúcho, marcado pela não-mestiçagem, constitui-se em uma ausência de contato com os grupos de baixa qualidade racial: "No Rio Grande do Sul, o fenômeno, muito acentuado, reveste-se de circunstâncias especiais, as quais excluem o cruzamento com as raças inferiores, verificado em outras regiões do país “(TRUDA, 1925, p. 245).

O pensamento de Truda sobre a formação de um determinado tipo de raça branca no sul do país, marcada pelo fenômeno da imigração européia, não destoa completamente da leitura de Oliveira Vianna sobre os diferentes tipos antropológicos que se constituiriam no interior da raça branca, ou branqueada. Pode-se inferir que para a formação de um tipo "sulista" existiria um contato menor - sempre no olhar do autor de "L'influenza étnica [...]"- com as populações negras e mestiças, as quais seriam progressivamente suplantadas pelos grupos brancos. A diferença maior se coloca na maneira como esse processo de elaboração de tipos brancos iria acontecer; enquanto para Truda - e mais adiante ver-se-á claramente as demonstrações práticas de suas idéias- as populações inferiores desapareceriam por extinção; para Vianna, a heterogeneidade das raças iria convergir para tipos diferenciados. Dessa maneira, os grupos não brancos acabariam subsumindo-se em meio a "raça superior", formando tipos regionais diversificados, adaptados as diferentes zonas do país:

Nestes termos, o "branqueamento" da população brasileira não era por ele concebido como a constituição de um tipo único e branco, mas pela progressiva perda de peso relativo dos descendentes de negros e índios no conjunto da população brasileira (RAMOS, 2003, p. 591).

O elemento forte que acomuna os dois autores, para além da dimensão prática de como promover uma melhoria racial da população brasileira, é o determinismo biológico e a inferioridade das raças não-brancas. Truda deixa claro seu pensamento quando destaca - com júbilo- que no Rio Grande do Sul não se observa nem mesmo uma "sombra de assimilação", mas uma exclusão que em breve tornar-se-á quase absoluta. Oliveira Vianna, por sua vez, destaca - a partir de uma análise diacrônica- a incapacidade negra de produzir civilização, o contínuo domínio do branco e a marca da mestiçagem com populações semitas dos grupos que ocupam espaços de poder no continente africano: 
O negro puro ... não foi nunca, pelo menos dentro do campo histórico em que o conhecemos, um criador de civilizações. Se, no presente, os vemos sempre subordinados aos povos de raça branca, com os quais entraram em contato; se, nos seus grupos mais evoluídos das regiões das grandes planícies nativas, são os elementos mestiços, são os indivíduos de tipo negróide, aqueles que trazem doses sensíveis de sangue semita, os que ascendem às classes superiores, formam a aristocracia e dirigem a massa dos negros puros (RAMOS, 2003, p. 595).

Segundo Leonardo Truda, o escravo já não vai encontrar espaço nas comunidades de imigrantes, desde a formação da colônia alemã de Linho Cânhamo, atual São Leopoldo, em 1825, pois aqueles que ali viviam, tinham sido expulsos e se dispôs que não deveriam retornar. Mais adiante, referindo-se aos primórdios da imigração italiana, destaca que o escravo constituir-se-ia em um elemento de perturbação econômica para as famílias, gravando sobre a economia doméstica. Assim, ressalta historicamente- uma tendência à separação entre os grupos de escravos - negros- e os grupos europeus, mantida, no caso específico dos italianos, nestes cinqüenta anos de "colonização". Todavia, segundo o autor, isso não representa um desdenho para com a população local, pois o cruzamento com os grupos brancos nacionais não é rejeitado.

Dessa forma, o aumento percentual da população branca - no Rio Grande do Sul, a partir da leitura que o texto permite e lembrando que o autor prefere deixar que as informações falem por si- é um dado estatístico festejado: em 1872 - no Brasil, 38,1\% da população era branca, enquanto no Rio Grande do Sul, este percentual subia para 59,4\%; em 1890 - o percentual de brancos em âmbito nacional tinha subido para $59,4 \%$, mas o índice regional se colocava em 70,17\%. Não é informada a fonte dos dados, mas - de qualquer forma- são importantes como elementos da retórica de Truda para a produção de uma representação vitoriosa da imigração no sul do Brasil. Resta ainda informar que - no mesmo período- a população de negros do estado diminuiu de 18,3\% para 8,68\% (TRUDA, 1925, p. 246).

Uma pergunta permanece sobre a leitura de Francisco de Leonardo Truda: como irá acontecer esse processo especial de branqueamento? O autor não redige uma resposta, mas - tendo em vista a maneira como articula o texto- permite perceber o aumento gradativo das populações brancas vinculado a um gradual aumento vegetativo, marcado por uma fertilidade e resistência maiores. $\mathrm{O}$ argumento sobre o crescimento da população branca é seguido pela descrição da questão da natalidade e da mortalidade na região de colonização italiana e, também, naquela alemã, colocadas entre as mais férteis e com um menor índice de mortalidade do estado. Portanto, procriando mais e tendo uma perspectiva de vida maior, é um processo natural e matemático esse branqueamento gaúcho pela exclusão: aplicação da fórmula 
darwinista do processo evolutivo, substituindo o conceito de adaptação por aquele de supremacia.

Dando maior ênfase às qualidades desses imigrantes provenientes da Península Itálica, o texto salienta que, além de uma robusteza física, esses italianos também eram saudáveis sob a perspectiva moral, o que reforça uma leitura antropológica, da época, a respeito do tipo superior. Analisando o ano de 1924, até maio de 1925, destaca os números insignificantes de crimes acontecidos na zona de colonização italiana, especialmente se comparados com a realidade do estado e considerados relativos ao percentual de habitantes. Levando em conta a quantidade de delitos contra a propriedade, contra a honra, contra a vida e de lesões corporais, Truda exalta a qualidade moral observada nas cidades formadas pela imigração italiana:

Assim, esses dados constituem, como dizíamos mais acima, o atestado mais expressivo da excelente índole, da alta moralidade de costumes e do espírito de ordem da população de origem italiana (TRUDA, 1925, p. 250).

A leitura que Francisco de Leonardo Truda apresenta - dialogando com as representações construídas sobre os imigrantes italianos no Rio Grande do Sul e no Brasil, na década de 1920 - insere-se no caldo das discussões em âmbito nacional e internacional sobre raça, determinismo biológico, questões climáticas e assimilação. Se, como afirmava Oliveira Vianna, o Brasil era o lugar privilegiado para uma análise científica das questões raciais, apenas vistas teoricamente na Europa, o Rio Grande do Sul - analisado por Truda- constitui-se em um espaço especial no contexto brasileiro, tendo em vista a força relativa do fenômeno imigratório. Certamente, de acordo com seu entendimento, a análise da experiência sulina poderia servir para evidenciar formas de aceleramento na construção de uma nação brasileira branca.

Em um percurso de exclusão das populações afro-brasileiras, o qual apresentou ao longo da história do Brasil independente diferentes facetas, passando pela invisibilidade e pela miscigenação regeneradora, o texto L'influenza etnica, sociale ed economica della colonizzazione italiana nel Rio Grande del Sud "ensina" uma nova tecnologia, o apartamento. Em uma leitura marcada pelo cientificismo da época e por uma permanência de características teóricas da antropologia física, Leonardo Truda destaca a eficácia do processo de transformação racial que se estava vivendo no Rio Grande do Sul como fruto de uma não miscigenação, mas de uma separação que garantia o progressivo aumento percentual da população branca, tendo em vista sua superioridade moral e física. 


\section{Referencias}

ALENCASTRO, Luiz Felipe; RENAUX, Maria Luiza. Caras e modos dos migrantes e imigrantes. In: NOVAIS, Fernando A.; ALENCASTRO, Luiz Felipe de. História da vida privada no Brasil: império: a corte e a modernidade nacional. São Paulo: Companhia das Letras, 1999. p. 291-335.

ANDREWS, George Reid. Negros e brancos em São Paulo (1888-1988). São Paulo: EDUSC, 1998.

BACZKO, Bronislaw. Los imaginarios sociales: memorias y esperanzas colectivas. Buenos Aires: Ediciones Nueva Visión, 1991.

BENEDUZI, Luís Fernando. Mal di paese: as reelaborações de um Vêneto imaginário na ex-colônia de Conde d'Eu (1884-1925). 2004. Tese (Doutorado em História) Universidade Federal do Rio Grande do Sul, Porto Alegre.

CASTAÑEDA, Luzia A. Eugenia e casamento. História, Ciências, Saúde-Manguinhos, Rio de J aneiro, v. 10, n. 3, p. 901-930, set./ dez. 2003.

HOUAISS, Antônio. Dicionário Eletrônico Houaiss da Língua Portuguese. versão 2.0. Objetiva, 2007.

GOMES, Tiago de Melo. Problemas no paraíso: a democracia racial brasileira frente à imigração afro-americana (1921). Estudos Afro-Asiáticos, Rio de J aneiro, ano 25, n. 2, p. 307-331, 2003.

PESAVENDO, Sandra. Modernità 'primitivista': dopo gli indiani, i neri. Appropriazioni, risentimenti e invenzioni. In: GOLINELLI, Gilberta (Ed.). Il primitivismo ele sue metamorfosi: archeologia di un discorso culturale. Bolonha, CLUEB: 2007.

RAMOS, J air de Souza. Ciência e racismo: uma leitura crítica de raça e assimilação em Oliveira Vianna. História, Ciências, Saúde-Manguinhos, Rio deJ aneiro, v. 10, n. 2, p. 573-601, maio/ ago., 2003.

SANTOS, Ricardo V. A obra de Euclides da Cunha e os debates sobre mestiçagem no Brasil no início do século XX: os sertões e a medicina-antropologia do Museu Nacional. História, Ciências, Saúde-Manguinhos, Rio deJaneiro, v. 5, p. 237-253, jul. 1998.

SCHWARCZ, Lilia Moritz. As barbas do imperador: D Pedro II, um monarca os trópicos. São Paulo: Companhia das Letras, 1998.

SEYFERTH, Giralda. Construindo a nação: hierarquias raciais e o papel do racismo na política de imigração e colonização. In: MAIO, Marcos; SANTOS, Ricardo (Ed.). Raça, Ciência e Sociedade. Rio de Janeiro: FIOCRUZ, 1996. p. 41-58.

SOVIK, Liv. Apresentação para ler Stuart Hall. In: HALL, Stuart (Ed.). Da diáspora: identidades e mediações culturais. Belo Horizonte: UFMG, 2003.

TRUDA, Francisco de Leonardo. A colonisação allemã no Rio Grande do Sul. Revista do Instituto Histórico e Geográfico do Rio Grande do Sul, Porto Alegre, Ano 10, n. 1, p. 163-312, 1930. 
TRUDA, Francisco de Leonardo. L'influenza etnica, sociale ed economica della colonizzazione italiana nel Rio Grande del Sud. In: CINQUANTENARIO della colonizzazione italiana nel Rio Grande Del Sud: la cooperazione degli italiani al progresso civile ed economico del Rio Grande del Sud. Porto Alegre: Livraria do Globo, 1925. p. 245-255.

Colaboração recebida em 31/ 05/ 2010. 